\title{
IT Service Management System Measurement using ISO20000-1 and ISO15504-8: Developing a Solution-Mediated Process Assessment Tool to Enable Transparent and SMS Process Assessment
}

\author{
Imam Asrowardi ${ }^{1}$, Septafiansyah Dwi Putra ${ }^{2}$, Eko Subyantoro ${ }^{3}$, Norzaidi Haji Mohd Daud ${ }^{4}$ \\ ${ }^{1,2,3}$ Department of Informatics Management, Politeknik Negeri Lampung, Indonesia \\ ${ }^{4}$ Arshad Ayub Graduate Business School, Universiti Teknologi MARA, Malaysia
}

\begin{tabular}{l} 
Article Info \\
\hline Article history: \\
Received Feb 19, 2018 \\
Revised Apr 11, 2018 \\
Accepted Apr 18, 2018 \\
\hline
\end{tabular}

Keyword:

Evaluation

IT-service

SLA

SMS

Tools

\begin{abstract}
Information technology is about not only hardware, software, communication infrastructure and communication infrastructure but also how to manage services. Information technology plays an increasingly important role in developing the structure and functions of public and private sectors. Service measurement plays an important role in IT service management (ITSM) that is one of the subfields of Services Computing science. ITSM is a big part of service science, a science field that combines computer science, operation research engineering, business strategy, management science, and organizational theory. Performance measurement from each of IT services is absolutely needed and is important in the continuous development of ITSM. These research provide good technical knowledge about the measuring ITSM with some requirements. In this paper we suggest the metrics in each service processes enables organizations to predict a direction for active process enhancement and to identify if the goal of process can achieve. This objective process metrics based on ISO/IEC 15504-8 and PRM ISO/IEC 20000-4 refinement. The output of this research, in the form of metrics and tools for any type organizational use.
\end{abstract}

Copyright $\odot 2018$ Institute of Advanced Engineering and Science. All rights reserved.

Corresponding Author:

Imam Asrowardi, Informatics Management, Politeknik Negeri Lampung, Indonesia.

Email: imam@polinela.ac.id

\section{INTRODUCTION}

Information technology is about not only hardware, software, communication infrastructure and communication infrastructure but also how to manage services. Information technology plays an increasingly important role in developing the structure and functions of public and private sectors. Almost billion of money are being spent on the procurement of new technology with the aim to improve IT organization (Service delivery) as well as the quality of services delivered to customers. Although IT service often brings benefits to an organization, its implementation sometimes does fail [1].

Service measurement plays an important role in IT service management (ITSM) that is one of the subfields of Services Computing science. ITSM is a big part of service science, a science field that combines computer science, operation research engineering, business strategy, management science, and organizational theory. Many IT service organizations consider the measurement of IT service management processes, especially service processes, as a difficult task [1]. Difficulties are mainly due to the following four reasons: 1) IT organizations do not have a structured approach for measuring IT services and service management processes, 2) tools used by service support teams do not enable effective measurement, 3) IT service 
management standards and frameworks do not provide practical examples how to measure support processes, and 4) there are too many options what to measure in service management [2]. IT service management related about preparing, designing, implementing, developing, mainting IT services [2].

A lot of research was focusing on implementation and integration of IT service management processes in organizations. However, these studies mainly focus on the business and process point of view and technical perspective is missing. On the other hand, it is not mentioned explicitly on how to measure and ensure that every steps could help to increase the efficiency and effectiveness of ITSM implementation. Performance measurement from each of IT services is absolutely needed and is important in the continuous development of ITSM. These research provide good technical knowledge about the measuring ITSM with some requirements. This research will perform the collaboration and refinement related IT service, so that the matrix produced can be more practical for the implementation.

The problem will solve in this research is about how to measure every steps in ITSM. The measurement is to design a framework and model integrated to each of ITSM steps, from design to deployment. The research problem represent in these questions:

1. What are the best practices or framework for measuring an ITSM process with an integration and many progreess?

2. How metrics can be support the best practices or framework?

\section{LITERATURE REVIEW}

\subsection{IT governance}

IT governance recognized as an integral part of enterprise governance. It "consists of the leadership and organizational structures and processes that ensure that the organization's IT sustains and extends the organization's strategies and objectives" [3]. IT Governance is a system that aims to control and direct IT service activities given by the service provider. The system encompasses policy, objective, planning, process, documentation and resources needed in a service cycle. The cycle consists of strategy, design, transition, operation and continuous improvement [4]. ISO/IEC 20000-1 states that the components of service management consist of [4]:

a. Strategy

1. Management responsibility.

2. Process governance by other parties.

3. Documentation management.

4. Resource management.

5. Service management system creation.

b. Design and transition

1. New service design or modification.

2. Design and development of a new or a modification of a service.

3. Transition of a new or a modification of a service.

c. Operation

1. Service delivery process: capacity management, service-level management, information security management, service availability and continuity management, service report, service budgeting and cost calculation.

2. Adjustment process: configuration management, change management, release and deployment management.

3. Resolution process: problem management, incident and service request management.

d. Continuous service improvement

\subsection{Service management system standard - ISO/IEC 20000:2011}

ISO/IEC 20000:2009 is the first international standard for IT service management (ITSM). This standard is based on and is intended to replace the British Standards BS 15000. This standard was first published in December 2005 and like its predecessor. BS 15000, was originally developed to describe the best practice guidance contained within the ITIL framework (Information Technology Infrastructure Library) standard although it also supports ITSM framework and other approaches. The latest version is currently the second edition of which is the development of ISO/IEC 20000:2011. ISO/IEC 20000:2011 consists of two main parts in the service management certification standards. The first part is a standard specification for the achievement of IT service management with the implementation rules for the management service. The first part, ISO/IEC 20000-1, advocated the use of an integrated process approach to effectively provide the appropriate managed service business and customer needs. The second part, ISO/IEC 20000-2, is a 'code of 
conduct' and describes the best practices for service management within the scope of ISO/IEC 20000-1 as shown in Figure 1.

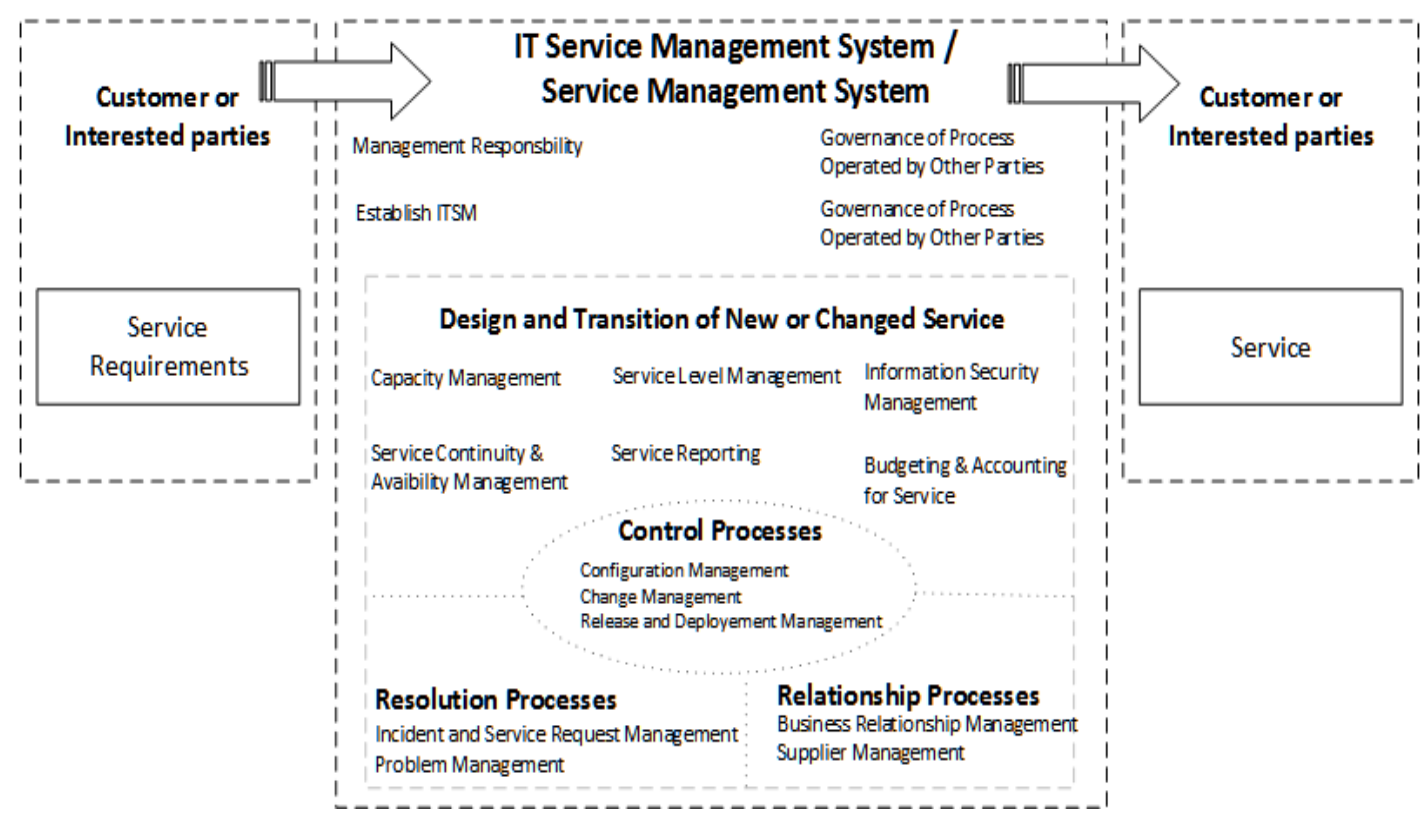

Figure 1. Service management system ISO/IEC 20000-1:2011

\subsection{Refinement PRM ISO/IEC 20000- 1:2011}

This process reference model (PRM) is a logical representation of the elements of the processes within service management. Using the PRM in a practical application might require additional elements suited to the environment and circumstances. The PRM specified in this part of ISO/IEC 20000 describes at an abstract level the processes including the general service management system (SMS) processes implied by ISO/IEC 20000-1. Each process of this PRM is described in terms of a purpose and outcomes. The PRM does not attempt to place the processes in any specific environment nor does it pre-determine any level of process capability required to fulfil the ISO/IEC 20000-1 requirements. Table 1 shows the example of refinement PRM for ISO/IEC 2000-1:2011.

Table 1. Example of Refinement PRM for ISO/IEC 2000-1:2011

\begin{tabular}{ll}
\hline \multicolumn{1}{c}{ Process ID } & SMS 2. \\
\hline Name & SMS Governance of processes operated by other parties \\
& The purpose of the Governance of processes operated by other parties process is to \\
& ensure the services supplied by other parties are managed to meet the service \\
& requirements; \\
As a result of successful implementation of this process: \\
1.The objectives and requirements for service Management are identified and \\
established to satisfy business needs, the service provider's financial processes, \\
regulatory, contractual and statutory. \\
2.Services supplied by other parties are managed to meet the service requirements; \\
SMS.2.1, Identify the objectives and requirements for service \\
mase \\
management. The objectives and requirements for service management are identified \\
and established to satisfy business needs, the service provider's financial processes, \\
and regulatory, contractual and statutory requirements.[Outcome 1] SMS.2.2, Manage \\
services provided by other suppliers. Services supplied by other parties are managed to \\
meet the service requirements. [Outcome 2] \\
12-01 Alternative party process requirements [Outcome 2] \\
Outputs
\end{tabular}




\subsection{Process assesment model ISO/IEC 15504-8}

Process assessment model (PAM) is a method of measuring a process consisting of indicators of process capability and process performance. Indicators of process capability is the ability of the process to achieve the level of capability that is determined by the attributes of the process. Evidence of indicators of process capability will support the assessment of the achievement of the process attributes.

A PAM comprises a set of indicators of process performance and process capability. The indicators are used as a basis for collecting the objective evidence that enables an assessor to assign ratings. The set of indicators included in this part of ISO/IEC 15504 is not intended to be an all-inclusive set nor is it intended to be applicable in its entirety [5], [6]. Figure 2 shows the relationship between the PAM and its inputs [4].

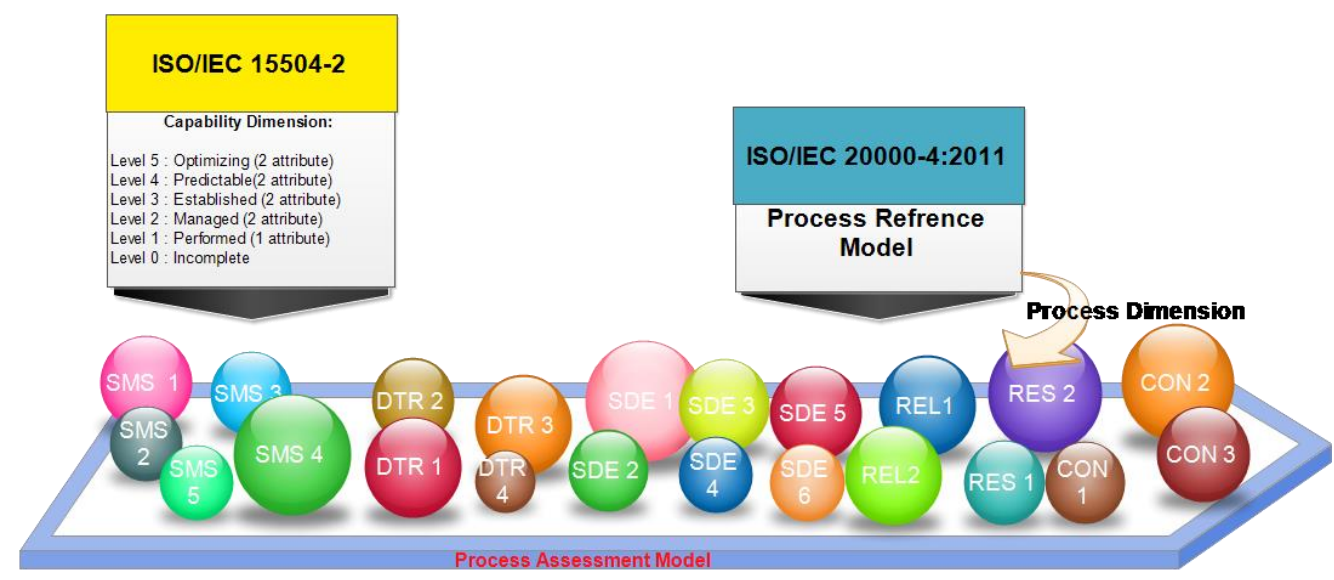

Figure 2. Relationship between the PAM and its inputs [4]

Assessment activities performs to distinguish between levels 1 to a higher level. This is done because the level 1 determines whether a process reaches its destination, and therefore it is very important to achieve, and also the basis for reaching a higher level. The results obtained at each level will be categorized into four classifications as shown in Table 2.

Table 1. The Four-Point Attribute Rating Scale

\begin{tabular}{|c|c|}
\hline Rating and Designation & Description \\
\hline $\mathrm{N}$ (Not achieved), & $\begin{array}{l}\text { There is no evidence of achivement for defined attribute. The number } \\
\text { value achieved in this classification range } 0-15 \% \text {. }\end{array}$ \\
\hline $\mathrm{P}$ (Partially achieved/ achieved in part), & $\begin{array}{l}\text { There is some achivement of the defined attribute. The number value } \\
\text { achieved in this classification range 15-50\%. }\end{array}$ \\
\hline L (Largely achieved) & $\begin{array}{l}\text { There is significant achivement of the defined attribute. The number } \\
\text { value achieved in this category ranges from } 50-85 \% \text {. }\end{array}$ \\
\hline F (Fully achieved / fully achieved), & $\begin{array}{l}\text { In this classification, there is full achivement of the defined attribute. } \\
\text { The number value achieved in this category range from } 85-100 \% \text {. }\end{array}$ \\
\hline
\end{tabular}

There are six capability levels [7]. At each level there is no ordering between the process attributes; each attribute addresses a specific aspect of the capability level [7]. The list of process attributes was showing in Table 3. PAM provide the basis for determining whether process attributes have achive:

a. Capability Level 1 - Indicators are specific for each process and assess whether the following Table 3 shows the attribute has been achieved the implemented process achieves its process purpose.

b. Capability Levels 2 to 5 - Assessment of capability is based from generic process indicators of performance. These are called generic because they apply across all processes, but they are different from one capability level to another. 
Table 2. Capability Levels and Process Attribute

\begin{tabular}{|c|c|}
\hline Process Attribute & Capability Levels and Process Attributes \\
\hline & $\begin{array}{l}\text { Level 0: Incomplete process, the process was not implementing and general failur to attain its } \\
\text { process purpose. }\end{array}$ \\
\hline & $\begin{array}{l}\text { Level 1: Performed process, the purpose of process was achieve. The achivement may not be } \\
\text { tracked or planned. }\end{array}$ \\
\hline \multirow[t]{2}{*}{ PA 1.1} & Process performance \\
\hline & $\begin{array}{l}\text { Level 2: Managed process, the process delivers work products of acceptable quality and } \\
\text { defined by timescale. The primary of process related work products are appropriately } \\
\text { established, controlled and maintained. }\end{array}$ \\
\hline PA 2.1 & Performance management \\
\hline \multirow[t]{2}{*}{ PA 2.2} & Work Products management \\
\hline & $\begin{array}{l}\text { Level 3: Established process, the previously described managed process was implementing } \\
\text { using a defined process that is capable of achieving its process outcomes. }\end{array}$ \\
\hline PA 3.1 & Process definition \\
\hline \multirow{2}{*}{ PA 3.2} & Process deployment \\
\hline & $\begin{array}{l}\text { Level 4: Predictable process, the defined process was performing consistently in practice } \\
\text { within defined limits to achieve its process outcomes }\end{array}$ \\
\hline PA 4.1 & Process measurement \\
\hline \multirow[t]{2}{*}{ PA 4.2} & Process Control \\
\hline & $\begin{array}{l}\text { Level 5: Optimizing process, the defined process was optimizing to meet curent and future } \\
\text { businnes needs. This process also consistently in practice within defined limits to achieve its } \\
\text { work products and outcomes. }\end{array}$ \\
\hline PA 5.1 & Process innovation \\
\hline PA 5.2 & Continuous optimization \\
\hline
\end{tabular}

\section{RESEARCH METHODOLOGY AND IMPLEMENTATION}

This research uses concurrent embedded mixed method as its methodology. Generally, this research uses qualitative methodology by gathering qualitative data, literatures, and elaborating some best practices or standards to design IT service governance. The first phase is to do literature analysis to evaluate the assessment and the measurement process of IT service. The analysis is a qualitative method. But, on the last part, a quantitative method is used to prove the qualitative method. The method is only a small part of the whole qualitative process. It can be inferred that quantitative method is embedded in a qualitative method. The said method is illustrated in Figure 3.

\section{Concurrent Embedded Design}

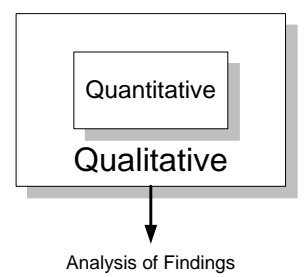

Figure 1. Research mehodology

After IT service measurement model is produced, quantitative validation is the next process on the line. Validation is carried on by using the model in assessing a case. Specifically, framework used in this research refers to a proactive research approach created by Cole $\mathrm{R}$, et al. That approach has four process steps that needs to be done in the research.

a. Problem identification is a process of defining a research problem and could cover the creation of initial concept that involves research objects.

b. Intervention is a planning, developing, and action taking process to make a construction, model, prototype, or other resources.

c. Evaluation is a process of observation and measurement of compatibility level and accuracy of produced output in order to support the solution of said problem. This process is a validation of model or design by using expert judgement.

d. Reflection and lessons learned. This is a process for produced output. The reflection and lessons learned aims to report the output of the research and to find its contribution to the practice and the theory.

In framework development phase, we start with placing the initial requirements as the direction in finding ITSM and IT service supporting theory literature. Theoretical model for designing metrics is showed 
in Figure 4. The outcome of the finding will be combined by the experiences from practicioner in this field and will be inserted into a measurement metrics. Framework in this integration is showed in Figure 5.

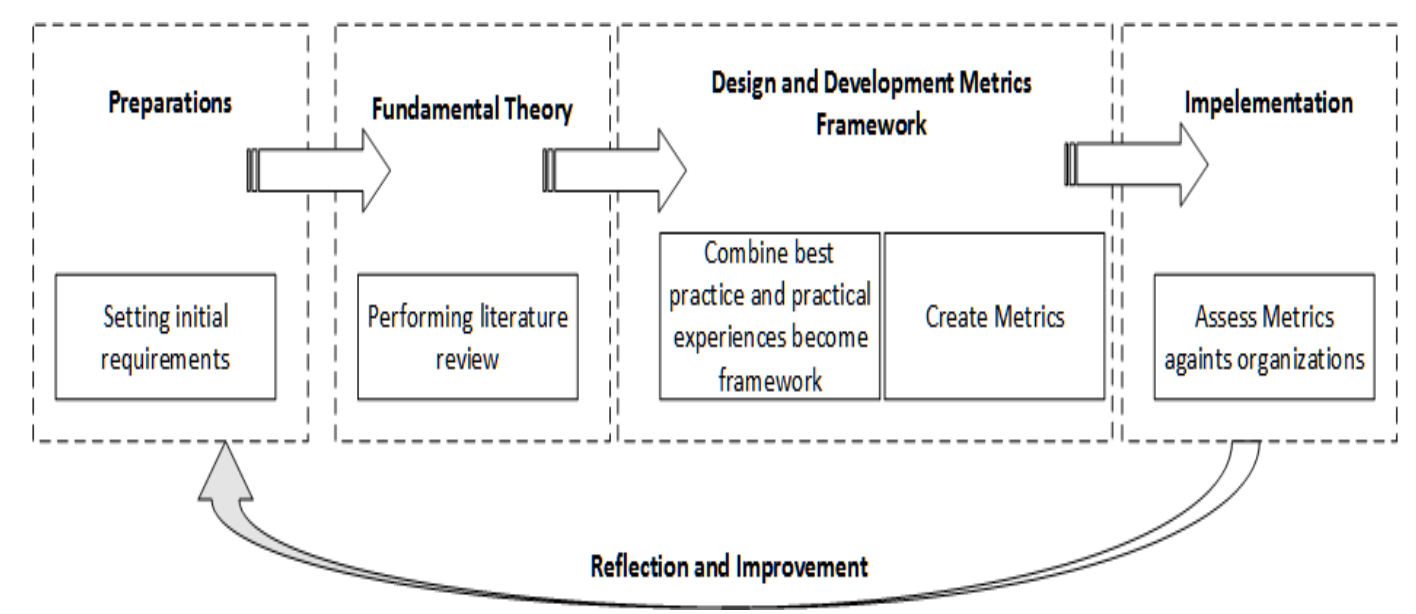

Figure 2. Theoretical model for designing metrics

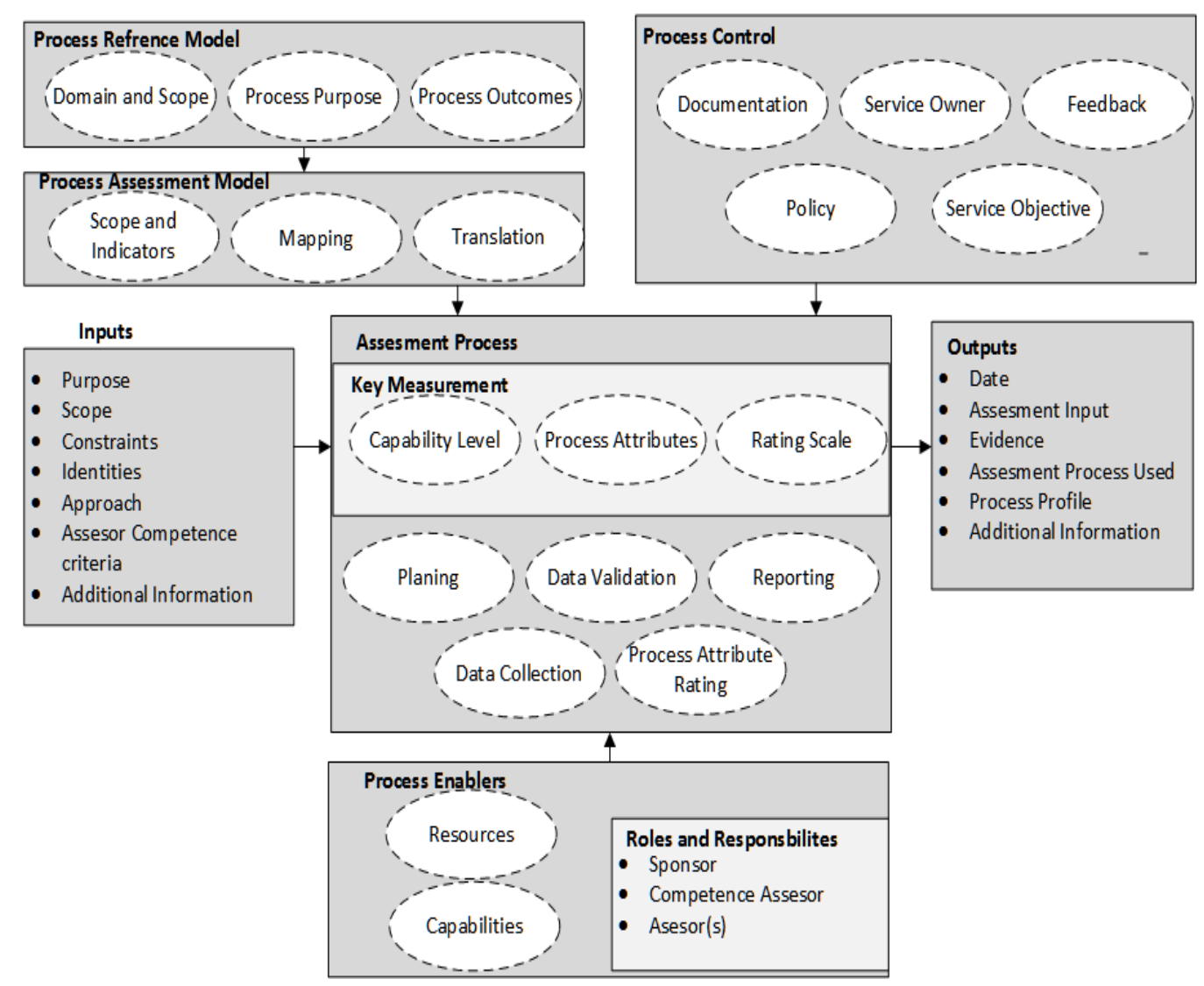

Figure 5. Framework element process

The next step in creating the metrics is to design Process Assessment Model (PAM) ISO/IEC 15504-8:2013 which is based on Process Reference Model (PRM) ISO/IEC 20000-4. PRM used in ISO/IEC 15504-8:2013 uses ISO/IEC 20000-1:2009 standard, so that researchers refines the PRM by improving its compatibility with ISO/IEC 20000-1:2013. It became the base of the state-of-the-art of our research. PAM 
from the refinement is used by researcher in doing appropriate conformant assessment to the requirements of ISO/IEC 15504-2 and ISO/IEC 20000-1:2013. The frame of mind in creating this evaluation tools is illustrated in Figure 6.

The components involved in designing a evaluation tools consist of process dimension, SMS processes list and capability dimension. Process dimension is a PRM process list that will be measured based on ISO/IEC 20000-4; each process contains the list of assessment component and the purpose to support the overall process of SMS.

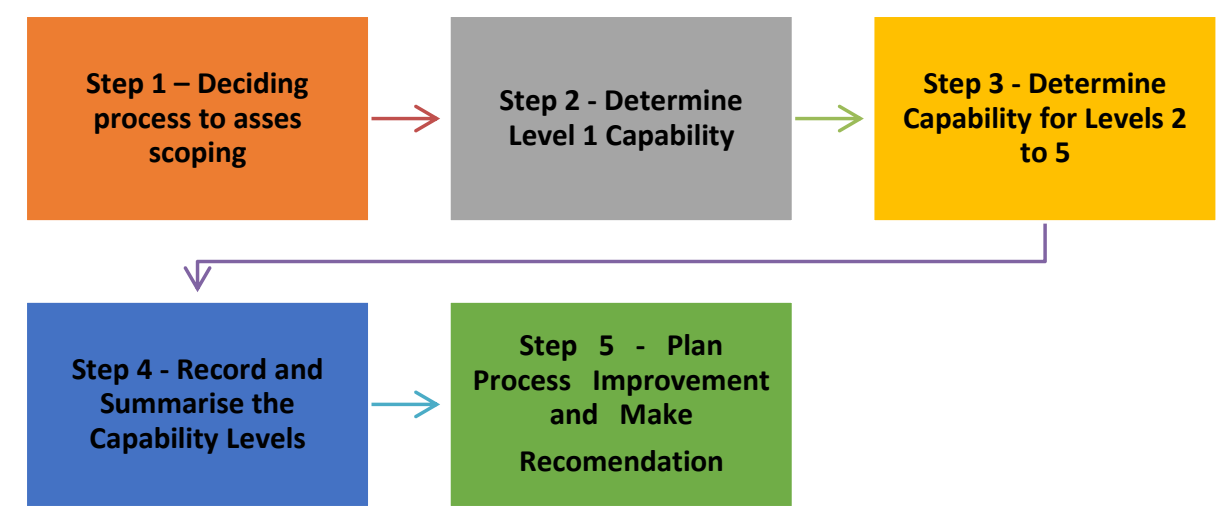

Figure 6. Framework implementation

\subsection{Element assesment process}

ISO/IEC 15504-1 suggest the assessment process contains at least five specified activities: planning, data collection, data validation, process attribute rating, and reporting. The assessment process must be documented; in addition, the assessors must record the objective indicators of performance or capability used to justify the ratings. A team carries out the process assessment with at least one competent assessor who has the competencies. An assessment is carried out by assessing selected processes against the assessment model(s) chosen for the assessment. The assessment model(s) have to be compatible with the requirements defined in ISO/IEC 15504-2. The Process Reference Model is selected according to the application domain of interest [6].

\subsection{Implementation tools}

A self-assessment by expert can identify process gaps that require improvements in advance of a formal assessment; it can be done for a relatively small investment and assists enterprise management in setting target capability levels.

1) Step 1 - Deciding process to asses scoping

Van Bon et al. (2008) explain the attributes to measure IT service process as a component. However, van Bon et al. (2007b) that a characteristic of modern ITSM is an end-to-end approach. The following attributes of an IT service can be used to measure quality:

1. Availability, ability of a service or service component to perform its required function at an agreed instant or over an agreed period of time

2. Capacity, current and forecast demand for services also expected impact of agreed requirements for availability, service continuity and service levels

3. Performance, the fulfillment of a claim, promise, or request of the services at planned intervals, with the customer

4. Security, preservation of confidentiality, integrity and accessibility of information

5. Confidentiality, containing information whose unauthorized disclosure.

6. Scalability, capable of being easily IT service to be expand or upgradeon demand

7. Adjustability, to bring IT service or process to a more satisfactory state

8. Portability, the quality or state the IT service of being portable

We tried to elaborate ITSM process and the attribute component into a table. 
Table 3. ITSM Process and Metrics to Measure

\begin{tabular}{|c|c|c|}
\hline ITSM Process & Metrics to Measure & Service Process Owner \\
\hline SMS 1. Management Responsibility & Availability, & Chief Information Officer \\
\hline SMS 2. Governance of Processes Operated & Performance, & Chief Information Officer \\
\hline SMS 3. Documentation Management & Adjustability, security, confidentiality & Release Manager \\
\hline SMS 4. Resource Management & Capacity, performance, availability & Capacity Manager \\
\hline SMS 5. Establish the SMS & Availability, capacity, adjustabilit & Service Desk Manager \\
\hline DTR 1. General & Performance, portability & Capacity Manager \\
\hline DTR 2. Plan New or Changed Services & Capacity, performance, availability & Configuration Manager \\
\hline $\begin{array}{l}\text { DTR 3. Design and Development of New or } \\
\text { Changed }\end{array}$ & $\begin{array}{l}\text { Capacity, performance, } \\
\text { Availability, scalability. }\end{array}$ & Configuration Manager \\
\hline DTR 4. Transition of New or Changed Services & $\begin{array}{l}\text { Capacity, performance, availability, } \\
\text { adjustability. }\end{array}$ & $\begin{array}{l}\text { Configuration Manager and } \\
\text { Change Manager }\end{array}$ \\
\hline SDE 1. Service level management & Availability, capacity & Release Manager \\
\hline SDE 2. Service Reporting & $\begin{array}{l}\text { Availability,capacity, performance, } \\
\text { security }\end{array}$ & Release Manager \\
\hline $\begin{array}{l}\text { SDE 3. Service Continuity and Avaibility } \\
\text { Management }\end{array}$ & Availability, performance & Release Manager \\
\hline SDE 4. Budgeting and Accounting for Services & Capacity, adjustability & Release Manager \\
\hline SDE 5. Capacity Management & Capacity, performance & Release Manager \\
\hline SDE 6. Information Security Management & Security, confidentiality, avaibility & Release Manager /CSO \\
\hline REL 1. Business Relationship Management & Avaibility, performance & Relationship Manager \\
\hline REL 2. Supplier Management & Avaibility, performance & Relationship Manager \\
\hline $\begin{array}{l}\text { RES.1 Incident and Service Request } \\
\text { Management }\end{array}$ & Security, confidentiality, avaibility & Incident Manager \\
\hline RES.2 Problem Management & $\begin{array}{l}\text { Security, confidentiality, avaibility, } \\
\text { capacity }\end{array}$ & Problem Manager \\
\hline CON.1 Configuration Management & Capacity, confidentiality, avaibility & Change Manager \\
\hline CON.2 Change Management & Scalability, portability & Change Manager \\
\hline CON.3 Release and Deployement Management & Scalability, portability, adjustability & Change Manager \\
\hline
\end{tabular}

The first step in the self-assessment is to decide what processes will to assess. Those processes selected and to have record in the table as shown in Table 5.

Table 4. Capability Levels and Process Attribute

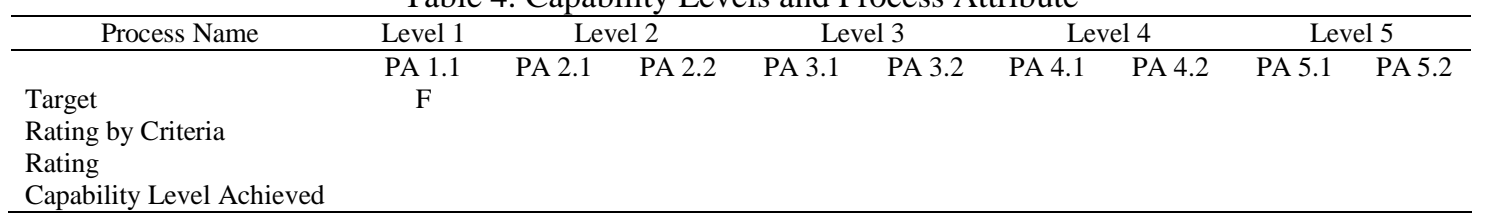

At this stage, the target process capability level can be recorded. This will establish the level of capability required of the process. In setting the target capability levels, consideration will give to the impact on the business objectives of the enterprise if a specified level of capability will not achieve. The first consideration is the impact on the enterprise if the process is non-existent or not working effectively or efficiently.

2) Step 2 - Determine Level 1 Capability

The first step in the assessment of each process is to determine whether a process is actually being performed and is achieving its outcomes. In the self-assessment worksheet Table 4 there is a table for each process. The indicators at capability level 1 are specific for each process and assess whether the following attribute has been achieved: The implemented process achieves its purpose.

3) Step 3 - Determine Capability for Levels 2 to 5

Above level 2, the assessment criteria are generic, i.e., the criteria are the same for each and every process. Again, in each case, a judgment must be made as to whether the criteria have been met, and that decision must be translated into a rating and recorded in the template for the process. This should be repeated for each capability until a capability level is rated as 'largely' or 'fully achieved'.

4) Step 4 - Record and Summarise the Capability Levels

The summary of assessment results should be recorded in Section 1. The capability level is determined at the level where both capability indicators are either 'largely' or 'fully achieved'. Those processes selected should be recorded in the table as shown in Table 4. 
5) Step 5 - Plan Process Improvement and Make Recomendation

Based on the self-assessment, consideration should be given to the development of a plan of action for process improvement. One option could be to commence an initial mprovement plan based on the selfassessment. This could address the areas of highest importance to the enterprise's business goals and focus on areas with gaps between the 'current' and 'target' process capability levels.

\subsection{Implementation}

We tried to the implement measurement metrics in an organizational unit of ICT service management in a higher education institution. Scope definition of evaluation by using this metrics encompasses main business processes of ICT services provided by the organization. The organization, currently, is functioning as a system support in delivering the services related to those activities.

The ITSM proceses - capability level assessment is carried on by gradually evaluate whether the processes are fulfilling the requirements on every level, from level 1 to level 5 . There are category provisoins of assessment result on every level, those are largely achieved (L) with range of score between 50-85\%, and fully achieved (F) with score range between $85 \%-100 \%$, so that the process can be declared that it has attained a capability level. The assessment is performed until the process achieve the expected level set by the organization.

From the outputs of metrics as shown in Figure 7. We argue the true value of IT service provision can only be realised when the services it provides are solutions to identified business needs that are both practical and reliable. In order to achieve this, these services need to be well managed. This improvement in the provision and management of services promotes the credibility of the industry while improving customer loyalty and satisfaction. Service providers must ensure their capacity to provide and manage identified services. This introspection is best performed in an environment that does not contain a customer.

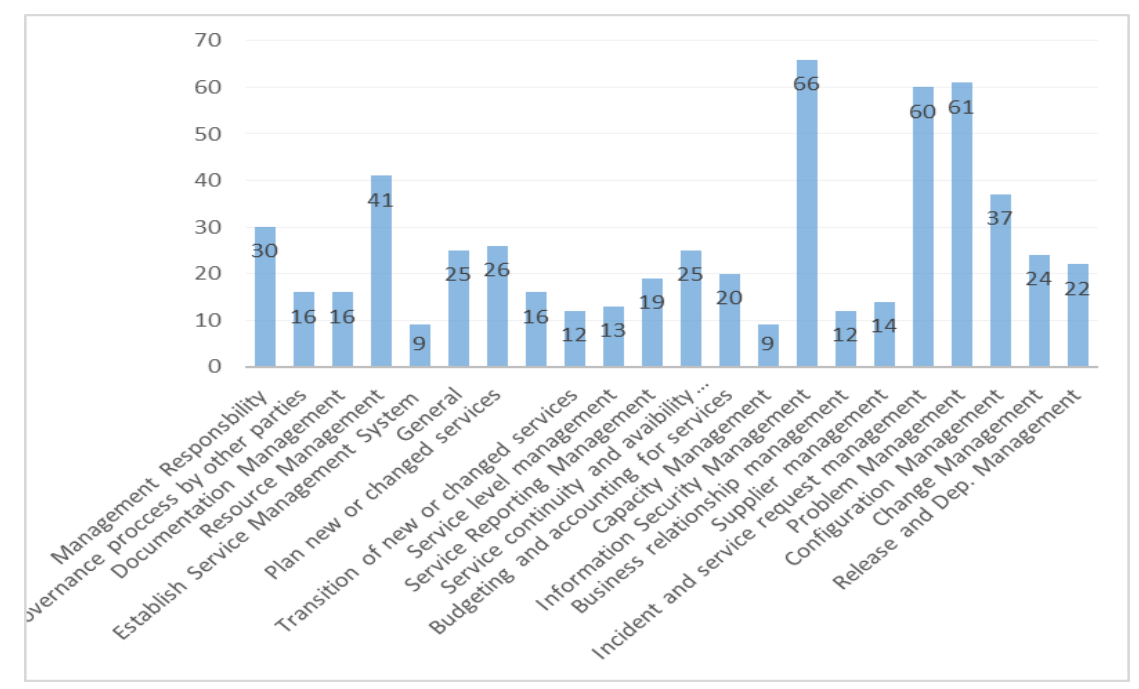

Figure 3. The assesment result using proposed metrics

\section{CONCLUSION}

In this paper we suggest the metrics in each service processes enables organizations to predict a direction for active process enhancement and to identify if the goal of process can achieve. This objective process metrics based on ISO/IEC 15504-8 and PRM ISO/IEC 20000-4 refinement, which has not been introduced in previous process assessment models, can be expected to measure process capability and to identify the risk, problems, and condition of process performance by using these metrics. This metrics provides a basis for use in IT service process improvement. From the results of this paper, following advantage can be obtained: facilitates self-assessment, produces a process rating for every ITSM process, and can raise formation's IT service management system process capability level. This metrics has already testing by author with implementation and justification by ITSM Expert at Polinela (higher education institution). The output of this research, in the form of metrics and tools for organizational use, can be downloaded in http://bit.ly/ITSMtools2018. 


\section{REFERENCES}

[1] K. Radha, et al., "Service Level Agreements in Cloud Computing and Big Data", International Journal of Electrical and Computer Engineering, vol. 5, pp. 158-165, 2015.

[2] M. A. M. Stambul and R. Razali, "An Assessment Model of Information Security Implementation Levels", in Electrical Engineering and Informatics (ICEEI), 2011 International Conference on, 2011.

[3] S. Buckby, et al., "The Current State of Information Technology Governance Literature", Information Science Reference (IGI Global), 2008.

[4] M. Mora, et al., "An Extensive Review of IT Service Design in seven International ITSM Processes Frameworks: Part I”, International Journal of Information Technologies and Systems Approach, vol. 7, pp. 83-107, 2014.

[5] ISO/IEC JTC 1, Information technology — Process assessment - ISO/IEC 15504 Part8.

[6] ISO/IEC JTC 1, Information technology — Process assessment - ISO/IEC 15504 part 1.

[7] Isaca, “COBIT Process Assessment Model (PAM): Using COBIT 5”, ISACA, 2011. 